oculists. The results of this search are disappointing, but as $\mathrm{Mr}$. Harvey Bloom says :- " "There is no period so difficult to trace people in as the late 17th and early 18th centuries."

I have thought it best to record all this negative evidence here in case any ophthalmic surgeon in the future should be tempted to try his hand at these three men, for it will save him much time and trouble knowing the search which has already been made.

\title{
ANNOTATIONS
}

\section{Blindness in India}

The Committee of the All-India Blind Relief Association, having its headquarters in Bombay, has sent us a copy 'of a letter which has been addressed to H. E. The Viceroy of India, together with pamphlets and other literature dealing with blindness in India.

Statistics as to the number of blind in India vary greatly; census returns show 1.5 per thousand for totally blind persons, but the Association has reasons for considering this figure far too low. Thus in 1918-19 in the Nasik district, for which census figures show an incidence of 1.74 per mille, an actual count in four talakas in villages with a population of 212,000 showed an incidence of at least 4.38 per mille. A few years ago a Deputy Commissioner in the United Provinces had a similar count made and discovered an incidence of no less than 9 per mille. In Palinpur an incidence of 7 per mille has been noted. The Association has reasons for believing that instead of the half million totally blind persons in India shown in the census returns, the true number is about treble. This refers to those totally blind in both eyes and takes no account of uniocular blindness. The Association, in an analysis of cases attending their camps and dispensaries, has found that for every totally blind person there are three with more or less damaged vision.

The fact that much of this blindness is preventable and that a great deal is remediable is commented on. Industrial accidents are, we believe, very rare in India and the main causes of blindness are cataract, glaucoma, untreated ophthalmia and neglected corneal ulcers. The Association points to the splendid work accomplished in Egypt by the ophthalmic services established, in the first place, through the generosity of Sir Ernest Cassell.

$\mathrm{Mr}$. Charles Henderson, I.C.S., would appear to have been the first to attempt to ameliorate this lamentable state of affairs in India, and now the All-India Blind Relief Association has been formed, with Mr. Henderson as President, in order to attempt 
to affiliate the various centres, to consolidate them under one head, and finally to improve and extend the work of blind relief. So far much has been accomplished by what we may call private endeavour, but lack of funds is the main stumbling block. It is obvious that private enterprise and generosity cannot cope with these enormous figures; and that, in the absence of any philanthropist among the wealthy Hindus coming forward with a donation similar to that of Sir Ernest Cassell in Egypt, the bulk of the funds necessary should be found by Government.

The Hon. ophthalmic surgeons to the Association are Dr. B. P. Banaji, F.R.C.S.I., who has contributed occasionally to our columns, and Dr. B. H. Pesikaha.

The subject is one that might well be brought to the notice of the recently formed International Association for the Prevention of Blindness.

\section{The International Association for the Prevention of Blindness}

During the last few years the problem of the prevention of blindness has received widespread attention. Governments, municipal authorities and voluntary agencies have all initiated measures directed to this common goal. In this country Departmental Committees, after lengthy and searching enquiries, have issued reports and made recommendations to the authorities concerned, not wholly without success.

The Red Cross and other Societies in Europe, after a study by a provisional committee of the possibilities of international co-operation in the prevention of blindness, expressed the opinion that the time had arrived for definite movement of an international character towards this end. This Committee and the League of Red Cross Societies were joint conveners of a meeting held at Scheveningen, Holland, on the day following the termination of the International Ophthalmological Congress.

This meeting was attended by a large number of representatives of Red Cross Societies, Societies concerned with Public Hygiene, Infant Welfare, Prevention of Venereal Disease, Ophthalmology, etc. After a morning session at which the president of the meeting, General van Diehl, representative of the Red Cross Society of the Netherlands, addressed the meeting, and other representative speakers expressed their interest in the opjects of the assembly, a resolution " declaring it highly desirable to establish a permanent international organisation for the prevention of blindness," and recommending the formation of an "International Association for the prevention of Blindness," was proposed and carried by acclamation.

At an afternoon session the proposed "statutes" of the newly 